\title{
A transmembrane glycoprotein, gp38, is a novel marker for immature hepatic progenitor cells in fetal mouse livers
}

\author{
Sayuri Konishi • Kentaro Yasuchika • Takamichi Ishii • \\ Ken Fukumitsu • Naoko Kamo • Naoya Fujita • \\ Iwao Ikai • Shinji Uemoto
}

Received: 20 April 2010 /Accepted: 30 September 2010 /Published online: 20 November 2010 / Editor: J. Denry Sato

(C) The Author(s) 2010. This article is published with open access at Springerlink.com

\begin{abstract}
Previously, we clarified the surface antigen profiles of hepatic progenitor cells (HPCs) in fetal liver tissue as the $\mathrm{CD} 49 \mathrm{f}^{+} \mathrm{CD} 45^{-}$Thy $1^{-}$cell fraction. However, these cells were a heterogeneous cell population containing various stages of differentiation. This study aimed to detect more immature HPCs, using a novel surface antigen, gp38. After the collagenase digestion of fetal livers harvested from E13.5 to E18.5 fetal mice, HPCs were obtained and divided into two subpopulations using flow cytometry: gp38-positive HPCs, and gp38-negative HPCs. Both types of HPCs were characterized by immunocytochemistry and RT-PCR. The proliferative activity was compared by BrdU incorporation and 3-(4,5-dimethylthiazol-2-yl)-2,5-diphenyltetrazolium bromide (MTS) assay. Furthermore, the comprehensive gene expression was investigated by DNA
\end{abstract}

S. Konishi $\cdot$ K. Yasuchika $(\bowtie) \cdot$ T. Ishii $\cdot$ K. Fukumitsu $\cdot$

N. Kamo $\cdot$ I. Ikai $\cdot$ S. Uemoto

Department of Surgery,

Graduate School of Medicine Kyoto University,

54 Kawahara-cho Shogoin, Sakyo-ku, Kyoto 606-8507, Japan

e-mail: ikai@kuhp.kyoto-u.ac.jp

T. Ishii

Laboratory of Embryonic Stem Cell Research, Stem Cell

Research Center, Institute for Frontier Medical Sciences,

Kyoto University,

Kyoto, Japan

N. Fujita

Cancer Chemotherapy Center,

Japanese Foundation for Cancer Research,

Tokyo, Japan

I. Ikai

Department of Surgery, Kyoto Medical Center,

National Hospital Organization,

Kyoto, Japan microarray. Both types of HPCs expressed alpha-fetoprotein. However, the gp38-positive HPCs derived from E13.5 fetal livers did not express albumin or cytokeratin 19, while the gp38-negative HPCs did. DNA microarray revealed that some genes related to the Wnt signal pathway were up-regulated in the gp38-positive HPCs. Furthermore, Wnt3a had a proliferative effect on the gp38-positive HPCs. In conclusion, the gp38-positive HPCs derived from fetal liver tissue until E13.5 could therefore be candidates for hepatic stem cells in the fetal liver.

Keywords Hepatic stem cell $\cdot$ Hepatic progenitor cell . gp38 $\cdot$ Hepatocyte $\cdot$ Wnt

\section{Introduction}

Hepatic stem cells and hepatic progenitor cells (HPCs) are a potential cell source of cell therapy for liver diseases because of their highly proliferative activities (Kubota and Reid 2000; Crosby et al. 2001; Sandhu et al. 2001; Suzuki et al. 2002; Yin et al. 2002; Oertel et al. 2003; Petersen et al. 2003; Tanimizu et al. 2003). They are supposed to have bipotency to differentiate into hepatocytes and cholangiocytes. However, the accurate identification of hepatic stem cells, and also the relationship between hepatic stem cells and HPCs has still remained to be elucidated.

Previously, the surface antigen profiles of HPCs residing in the E13.5 fetal murine liver were clarified (Yasuchika et al. 2002) and they were isolated as the $\mathrm{CD} 49 \mathrm{f}^{+} \mathrm{CD} 45^{-}$Thy $1^{-}$ cells (CD49f-positive HPCs) using flow cytometry (Hoppo et al. 2004; Ishii et al. 2005). These cells showed a heterogeneous staining pattern of albumin and cytokeratin 19 (CK19), thus suggesting that they contained multiple populations of HPCs at various stages of differentiation 
(Hoppo, et al. 2004). A DNA subtraction analysis was conducted to identify the surface antigen that was specific for hepatic stem/progenitor cells and focused on gp38 (also known as podoplanin) because it is expressed in fetal livers but not in adult livers. Gp38 is a mucin-type transmenbrane glycoprotein and is well established as a lymphatic marker because of its specific expression in the endothelium of lymphatic capillaries but not in the blood vessel endothelium (Breiteneder-Geleff et al. 1999). Mesenchymal cells residing in fetal livers that were identified as $\mathrm{CD} 49 \mathrm{f}^{+} \mathrm{CD} 45^{-}$Thy $1^{+}$ cells (Thy1-positive mesenchymal cells) can be divided into two populations using the surface antigen gp38 (Kamo et al. 2007). The CD49f CD45 ${ }^{-}$Thy $^{+}{ }^{+}$gp $38^{+}$cells (gp38-positive mesenchymal cells) promoted in vitro maturation of HPCs, whereas the $\mathrm{CD} 49 \mathrm{f}^{-} \mathrm{CD} 45^{-} \mathrm{Thy}^{+}{ }^{+} \mathrm{gp} 38^{-}$cells (gp38-negative mesenchymal cells) played an inhibitory role on the maturation of HPCs. In other words, the gp38-negative mesenchymal cells maintain the immature, proliferative state of HPCs.

This study aimed to further fractionate the HPCs using gp38 in order to identify more immature HPCs, which could be putative hepatic stem cells. In addition, this study attempted to elucidate the mechanism that underlies the maintenance of the undifferentiated state of immature HPCs.

\section{Materials and Methods}

Animals. C57BL/6 J mice were obtained from SLC (Hamamatsu, Japan). The animals were maintained at a constant temperature of $18^{\circ} \mathrm{C}$ to $20^{\circ} \mathrm{C}$ and in a 12 -h light/ 12-h dark cycle. All experimental procedures utilizing animals were performed in accordance with the Animal Protection Guidelines of Kyoto University.

Isolation and culture of fetal liver cells. Fetal livers were obtained from embryonic d 11.5 (E11.5), E13.5, E15.5 and E18.5 fetal mice respectively and HPCs were enriched by the formation of cell aggregates. The isolation and culture of the cell aggregates was performed as described previously (Yasuchika et al. 2002; Hoppo et al. 2004). Briefly, fetal liver cells digested by $0.5 \%$ collagenase were cultured on Petri dishes, allowing cell aggregation. The cell aggregates were inoculated onto collagen type I-coated plates, followed by dissociation of the adherent cells using $0.25 \%$ trypsin-ethylenediaminetetraacetic acid solution (Sigma Chemical Co., Ltd., St. Louis, MO) after $24 \mathrm{~h}$ of culture. These cells were analyzed using FACSCalibur (BD Biosciences, Franklin Lakes, NJ).

Flow cytometry and cell sorting. Cultured fetal liver cells were sorted out by phycoerthrin (PE)-conjugated antiCD45, PE-conjugated anti-CD49f and fluoresceinconjugated anti-Thy1 antibodies using a flow cytometer (FACSVantage SE, BD Biosciences) as previously described (Hoppo et al. 2004; Ishii et al. 2005). Rat antimouse gp38 monoclonal antibody (8F11) was labeled by allophycocyanin according to the manufacturer's instructions (Kato et al. 2004). Dissociated cells were incubated with anti-gp38 diluted at $1: 100$ at $4^{\circ} \mathrm{C}$ for $30 \mathrm{~min}$ followed by rinsing with phosphate buffered saline (PBS). The sorted CD49f ${ }^{+} \mathrm{CD} 45^{-}$Thy $^{-}{ }^{-}$gp $38^{+}$cells (gp38-positive HPCs) and CD $49 f^{\dagger} \mathrm{CD} 45^{-}$Thy $^{-}{ }^{-} \mathrm{gp} 38^{-}$cells (gp38-negative HPCs) were cultured on collagen type I-coated 24-well plates at a density of $2 \times 10^{4}$ cells/well in Dulbecco's modified Eagle's medium (GIBCO-BRL, Grand Island, NY) supplemented with $10 \%$ fetal calf serum, $20 \mathrm{mmol} / 1 \mathrm{HEPES}, 25 \mathrm{mmol} / 1 \mathrm{NaHCO}_{3}$, $0.5 \mathrm{mg} / \mathrm{l}$ insulin, $1 \times 10^{-7} \mathrm{~mol} / 1$ dexamethasone (Wako, Osaka, Japan), $10 \mathrm{mmol} / \mathrm{l}$ nicotinamide (Wako), $2 \mathrm{mmol} / \mathrm{l}$ L-ascorbic acid phosphate (Wako), penicillin/streptomycin and $20 \mathrm{ng} / \mathrm{ml}$ hepatocyte growth factor (R\&D Systems, Minneapolis, MN).

Immunocytochemistry of cultured cells. After washing twice in PBS, the cultured cells were fixed in $4 \%$ paraformaldehyde (PFA) for $15 \mathrm{~min}$ at room temperature. Immunocytochemistry for alphãfetoprotein (AFP), albumin, and CK19 was performed as previously described (Yasuchika et al. 2002; Hoppo et al. 2004; Ishii et al. 2007; Kamo et al. 2007). To perform immunostaining for gp38, anti-mouse gp38 antibody (8.1.1: the hamster monoclonal antibody specific for gp38 was a kind gift of Dr. Andrew G. Farr, University of Washington School of Medicine, Seattle, WA)was used as a first antibody at a dilution of 1:10. Alexa 590-goat anti-hamster $\operatorname{IgG}$ (Molecular Probes, Inc., Eugene, OR) was used as a

Table 1. PCR primer sequences

\begin{tabular}{lll}
\hline Gene symbol & Forward primer & Reverse primer \\
\hline AFP & 5'-GAAGATGGTGAGCATTGCC & 5'-AACAGACTTCCTGGTCCTGG \\
Albumin & 5'-CGAGAAGCTTGGAGAATATGG & 5'-GTCAGAGCAGAGAAGCATGG \\
CK19 & 5'-GTGCCACCATTGACAACTCC & 5'-AATCCACCTCCACACTGACC \\
Desmin & 5'-GCTATCAGGACAACATTGCG & 5'-GTTGTTGCTGTGTAGCCTCG \\
$\alpha$-smooth muscle actin & 5'-CTATTCAGGCTGTGCTGTTCC & 5'-GGACCTCTTCTCGATGCTGA \\
$\beta$-actin & 5'-TCCTATGTGGGTGACGAGGC & 5'-TACATGGCTGGGGTGTGAA \\
\hline
\end{tabular}


Table 2. Quantitative PCR primer sequences

\begin{tabular}{lll}
\hline Gene symbol & Forward primer & Reverse primer \\
\hline AFP & 5'-CACACCCGCTTCCCTCAT & 5'-TTTTCGTGCAATGCTTTGGA \\
Albumin & 5'-TGGTGACCTGCTGGAATGC & 5'-AGTCGCCTGGTTTTCACACAT \\
CK19 & 5'-CCCTCCCGAGATTACAACCA & 5'-GCAAGGCGTGTTCTGTCTCA \\
GAPDH & 5'-CGGCCGCATCTTCTTGTG & 5'-ACCGACCTTCACCATTTTGTCT \\
\hline
\end{tabular}

second antibody at the dilution of 1:800. DAPI staining was performed according to the standard protocol. In order to stain the isolated cells just after the cell sorting, they were attached to slides by centrifugation at $1,000 \times g$ and then were fixed by $4 \%$ PFA. Thereafter, immunostaining was performed as described above. In every experiment, the expression ratio of AFP and albumin and CK19 were calculated in three independent fields and evaluated as the means \pm standard deviation (SD).

Reverse transcription polymerase chain reaction (RT$P C R)$. Total RNA was extracted from both the gp38positive HPCs and gp38-negative HPCs derived from E11.5, E13.5, and E18.5 fetal mice livers using an RNeasy Mini kit (Qiagen, Chatsworth, CA) and treated with RNase-free DNase (Qiagen). Total RNA $(0.065 \mu \mathrm{g})$ was reverse-transcribed into cDNA with oligo (dT) 12-18 primer (Invitrogen, Carlsbad, CA) using an Omniscript RT kit (Qiagen). PCR utilized Ex Taq polymerase (Takara Bio Inc., Otsu, Japan) according to the manufacturer's instructions. The primers used for amplification are listed in Table 1.

DNA microarray analysis. Total RNA was extracted from the gp38-positive HPCs and gp38-negative HPCs immedi- ately after cell sorting using an RNeasy Mini Kit (Qiagen) as described above. A microarray analysis was performed according to the standard protocol (Affymetrix GeneChip Manual, Affymetrix, Santa Clara, CA). Briefly, cRNA was synthesized from $100 \mathrm{ng}$ total RNA and then biotinylated using the two-cycle target labeling method. Fifteen $\mu \mathrm{g}$ cRNA were hybridized to a Mouse Genome 430 2.0 Array (Affymetrix). The array images were scanned using a GeneChip Scanner 3,000 (Affymetrix), after amplification and detection of the hybridized signals through the streptavidin-conjugated phycoerythrin fluorescence. The obtained data were analyzed using the GeneChip Operating Software program (Affymetrix). After experimental normalization, data mining was performed using the GeneSpring system (Agilent Technologies, Palo Alto, CA). A greater than a 2-fold expression level was assumed to be significant.

Cell proliferation assay. In bromodeoxyuridine (BrdU) incorporation assay, cultured cells were incubated with $10 \mu \mathrm{M}$ BrdU for $24 \mathrm{~h}$ and then incubated with $2 \mathrm{~N} \mathrm{HCl}$ for $1 \mathrm{~h}$ at $37^{\circ} \mathrm{C}$. Incorporated BrdU was detected by immunocytochemistry using an anti-BrdU antibody conjugated to horseradish peroxidase (Dako, Glostrup, Denmark). The peroxidase activity was determined by ENVISION KIT/
Figure 1. Flow cytometric and RT-PCR analyses of fetal mouse liver cells. (A) Flow cytometric fractionation of the cell aggregates derived from E13.5 fetal livers using anti-CD45, CD49f, and Thyl antibodies. The cell aggregates were composed of three fractions: a CD49f $\mathrm{f}^{+} \mathrm{CD} 45^{+}$Thy $1^{-}$ fraction (G1: CD45 positive hematopoietic cells), a CD49f ${ }^{+} \mathrm{CD} 45^{-}$Thy $^{-}$fraction (G2: CD49f-positive HPCs), and a CD49f ${ }^{+} \mathrm{CD} 45^{-}$Thy $^{+}$fraction (G3: Thy1-positive mesenchymal cells). (B) The CD49f-positive HPCs were further separated into two fractions using anti-gp38 antibodies. (C) An RT-PCR analysis of the gp38-positive HPCs (left) and the gp38-negative HPCs (right).
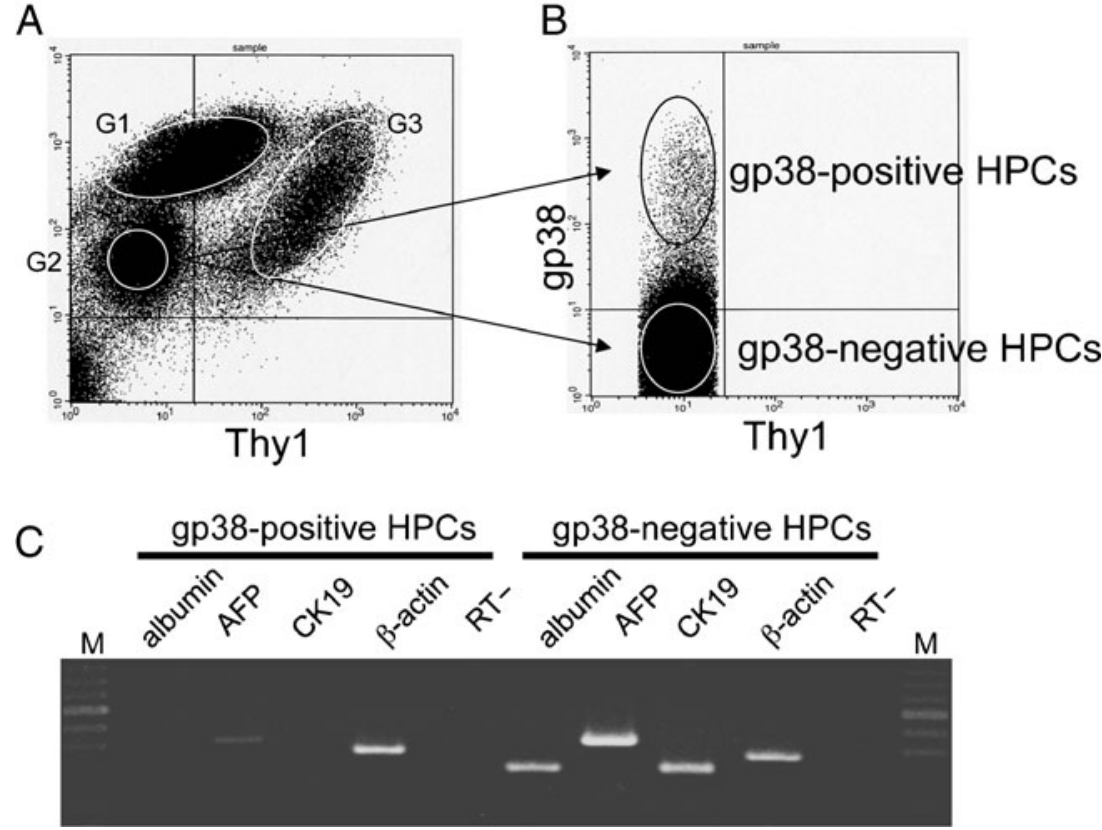
HRP (DAB) (Dako, Glostrup Denmark) according to the manufacturer's instructions. In every experiment, the ratio of BrdU incorporating cells was calculated in three independent fields and evaluated as the means $\pm \mathrm{SD}$.

The cell numbers of the gp38-positive and gp38negative cells were evaluated at $2 \mathrm{~d}$ and $10 \mathrm{~d}$ after cell sorting by the MTS assay (Cell Titer 96 Aqueous One Solution Reagent, Promega, Madison, WI), which was performed according to the manufacturer's protocol. After $2 \mathrm{~h}$ of incubation, the absorbance value at $490 \mathrm{~nm}$ was measured using a plate reader, and the doubling time of both the gp38-positive and gp38-negative HPCs was calculated in the presence or absence of the Wnt ligands.

Quantitative PCR. For quantitative PCR, total RNA was reverse-transcribed into cDNA using random primers (Invitrogen). Quantitative PCR was performed with 7,500 Fast Real-Time PCR System (Applied Biosystems, Foster City, CA) using SYBR Green PCR Master Mix (Applied Biosystems) according to the manufacturer's protocol. The quantified values of each gene were normalized against GAPDH expression using the comparative threshold cycle method. The primers used are listed in Table 2.

Statistical analysis. Statistical analysis was performed using Student's $t$ test. $P<0.05$ was identified to be statistically significant.

\section{Results}

Characterization of gp38-positive and gp38-negative HPCs. Flow cytometric analyses using anti-CD45, CD49f, Thy1, and gp38 antibodies showed that the fetal liver cells obtained from E13.5 fetal mouse liver tissues were divided into three fractions: a $\mathrm{CD} 49 \mathrm{f}^{+} \mathrm{CD} 45^{+} \mathrm{Thy}^{-}$ fraction (G1: CD45 positive hematopoietic cells), a CD49f $\mathrm{f}^{+} \mathrm{CD} 45^{-}$Thy $^{-}$fraction (G2: CD49f-positive HPCs), a CD49f ${ }^{+} \mathrm{CD} 45^{-} \mathrm{Thy}^{+}$fraction (G3: Thy1-positive mesenchymal cells) as described in our previous reports (Hoppo et al. 2004; Kamo et al. 2007; Fig. 1A). Furthermore,

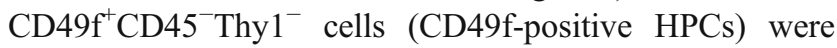
divided into two cell populations: $\mathrm{CD} 49 \mathrm{f}^{+} \mathrm{CD} 45^{-} \mathrm{Thy}^{-}{ }^{-} \mathrm{gp} 38^{+}$ cells (gp38-positive HPCs) and $\mathrm{CD}_{4} 4 \mathrm{f}^{+} \mathrm{CD} 45^{-} \mathrm{Thy}^{-}{ }^{-} \mathrm{gp} 38^{-}$ cells (gp38-negative HPCs; Fig. 1B). The fraction of $98.3 \pm$ $0.3 \%$ of the CD49f-positive HPCs was negative for gp 38 , however; approximately $1.7 \pm 0.3 \%$ of the CD49f-positive HPCs expressed gp38. RT-PCR analyses revealed that AFP was expressed in both the gp38-positive and gp38-negative HPCs. Although the gp38-negative HPCs expressed both albumin (a hepatocyte marker) and CK19 (a cholangiocyte marker), the gp38-positive HPCs expressed neither of them
(Fig. 1C). Immunocytological assays revealed that the sorted gp38-positive HPCs were positive for gp38 and negative for Thy1 (Fig. 2A,C), whereas the sorted gp38-negative HPCs were negative for both gp 38 and Thy1 (Fig. $2 B, D$ ). With regard to the expression of differentiation markers of hepatic endoderm, AFP, albumin, and CK19 were detected as much as $100 \pm 0 \%, 4.0 \pm 6.9 \%$ and $5.7 \pm 4.9 \%$, respectively in the gp38-positive HPCs (Fig. 2E, G, I). On the other hand, the

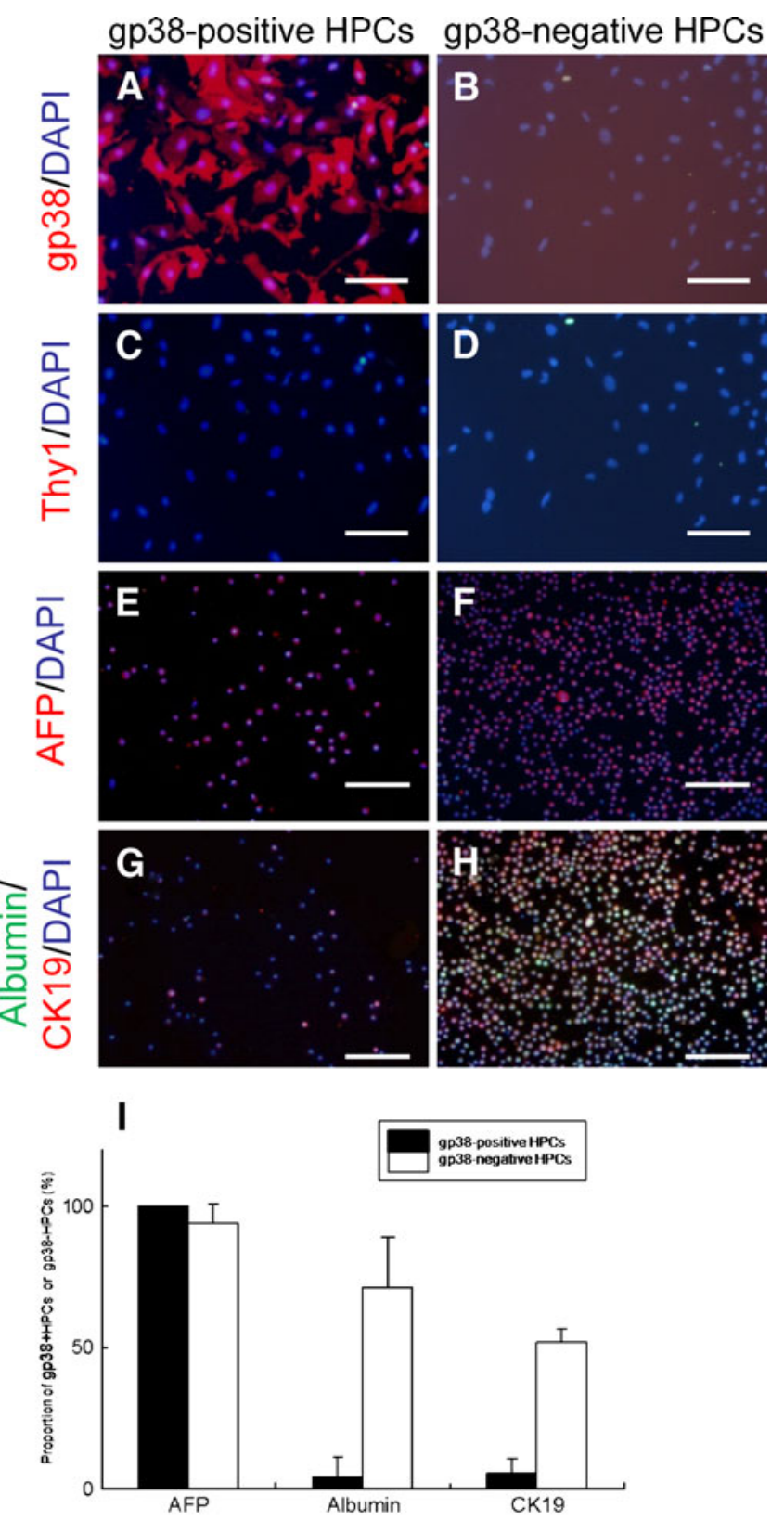

Figure 2. Immunocytological analyses of the gp38-positive (left $)$ and gp38-negative HPCs (right) of E13.5. Each of them was stained for gp38 $(A, B)$ Thy1 $(C, D)$, AFP $(E, F)$, and albumin with CK19 $(G, H)$. Blue fluorescence represents the staining of DAPI. The graph represents the proportion of AFP-, albumin-, and CK19-positive cells in both the gp38-positive and gp38-negative HPC fractions (E13.5) (I). Scale bars indicate $100 \mu \mathrm{m}$. 
Table 3. Doubling time of the gp38-positive and gp38-negative HPCs in the presence or absence of Wnt signaling stimulation

\begin{tabular}{llll}
\hline & Without Wnt3a & With Wnt3a & $P$ \\
\hline gp38-positve HPC & $172.9 \pm 109$ & $57.1 \pm 10.8$ & 0.057 \\
gp38-negative HPC & $814.2 \pm 566.8$ & $520.3 \pm 251.6$ & 0.089 \\
$P$ & 0.063 & 0.016 & \\
\hline
\end{tabular}

The number represents the doubling time ( $\mathrm{h}$, the mean $\pm \mathrm{SD} ; n=4$ )

gp38-negative HPCs expressed AFP, albumin, and CK19 as much as $94.0 \pm 7.0 \%, 71.3 \pm 17.6 \%$ and $51.7 \pm 4.7 \%$, respectively (Fig. $2 F, H, I$ ). These findings suggested that a majority of the gp38-positive HPCs had undergone neither hepatocyte nor cholangiocyte differentiation in comparison to the gp38-negative HPCs.

MTS assay revealed that the doubling time of the gp38-positive HPCs tended to be shorter than that of the gp38-negative HPCs (Table 3). Furthermore, $84.7 \pm 3.5 \%$ of the gp38-positive HPCs incorporated BrdU (Fig. 3A,C), whereas only $18.1 \pm 5.4 \%$ of the gp38-negative HPCs did (Fig. 3B, C). These findings suggested that the gp38-positive HPCs had a higher proliferative activity than the gp38negative HPCs.

Time course analysis of the gp38-positive HPCs. In order to examine the behavior of both types of HPCs in the different embryonic stage livers, the proportion of the gp38positive HPCs were measured at E11.5, E13.5, E15.5, and E18.5, respectively. Although the proportion of the gp38positive cells decreased as the fetal liver developed until E13.5, it increased abruptly at E18.5 (Fig. 4A). Immunocytological staining was performed to characterize the gp38-positive and gp38-negative HPCs in the E18.5 fetal liver. Although a large number of the gp38-positive HPCs were still positive for AFP, namely as much as $82.1 \pm 13.9 \%$ (Fig. 4B, F), the expression of albumin and also CK19 were up-regulated to $25.9 \pm 21.4 \%$ and $79.2 \pm 7.6 \%$, respectively (Fig. 4D, F). On the other hand, the gp38-negative HPCs no longer expressed AFP as much as $0.05 \pm 0.1 \%$ (Fig. $4 C, F$ ), whereas the expression of albumin and CK19 were also increased up to $66.3 \pm 13.0 \%$ and $98.7 \pm 0.9 \%$, respectively (Fig. 4E, F). These findings suggested that the gp38-positive HPCs at E18.5 were different from those at E13.5.

DNA microarray analysis of the gp38-positive and gp38negative HPCs. In order to clarify the molecular mechanisms underlying the undifferentiated state of the gp38-positive HPCs, comprehensive gene expressions were compared among the gp38-positive and gp38-negative HPCs derived from E13.5 fetal liver using DNA microarray. The microarray analyses revealed that the Wnt4, 5a, 5b, 9a, 11, frizzled homolog (Fzd) 1, 2, 8, and 10 genes were expressed preferentially in the gp38-positive HPCs, whereas the Foxa2,
Figure 3. BrdU uptake of the gp38-positive and gp38negative HPCs. The cells with brown stained nucleus represent BrdU incorporated cells in the gp38-positive HPCs $(A)$, and those of the gp38-negative HPCs $(B)$. The graph represents the proportion of the uptake of $\operatorname{BrdU}(C, * ; P=0.001$, tested by Student's $t$ test). Scale bars indicate $100 \mu \mathrm{m}$. gp38-positive HPCs
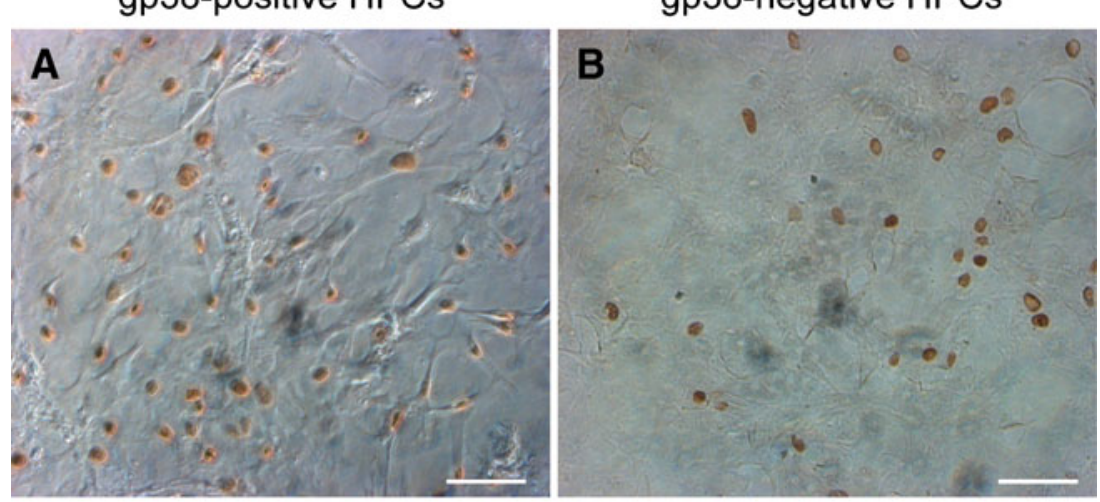

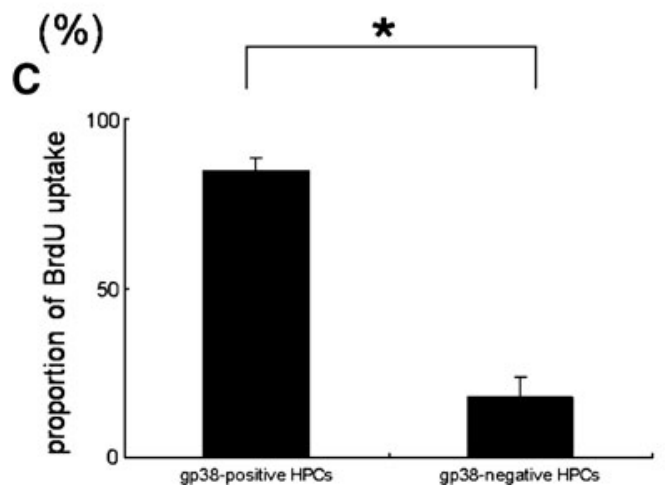



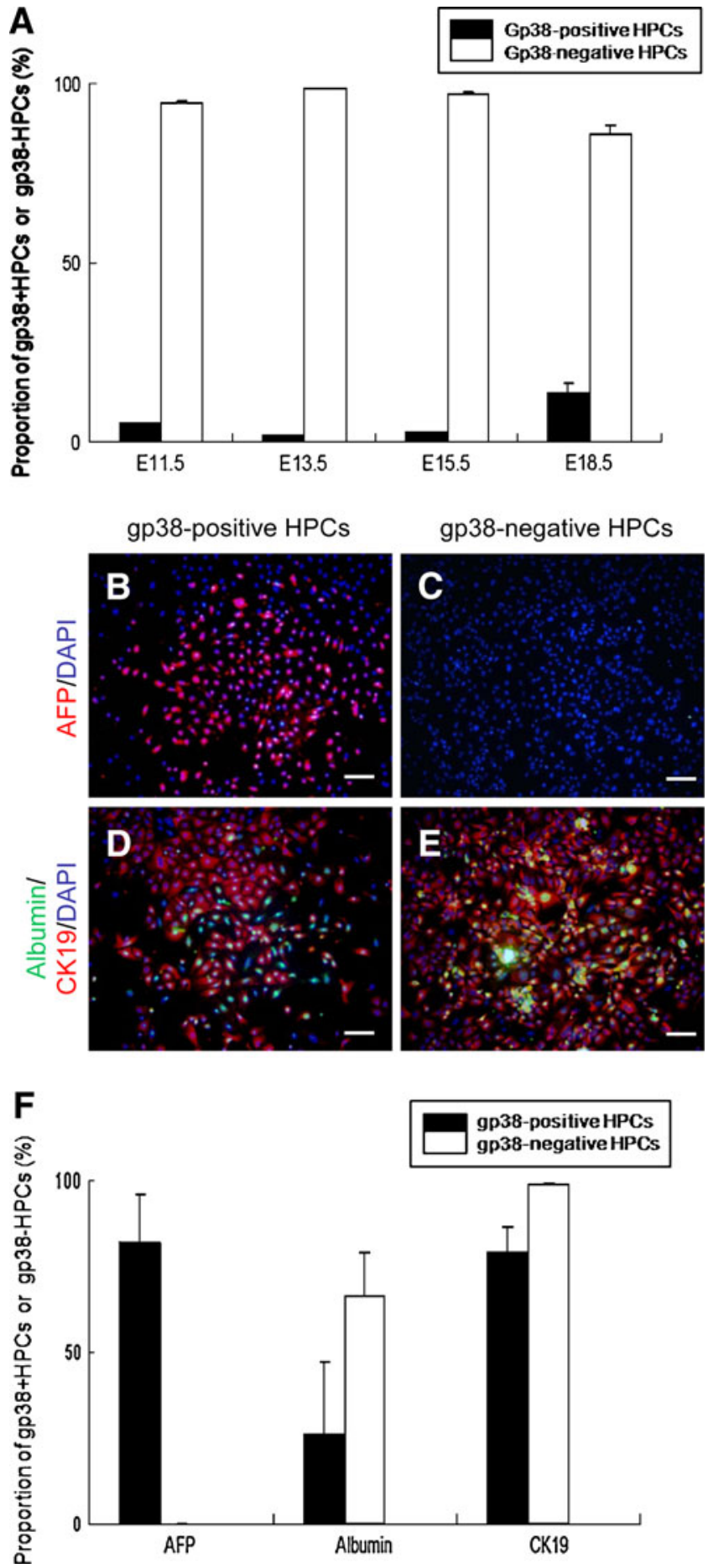

Figure 4. The time course analyses of the gp38-positive and gp38negative HPCs. (A) The graph indicates the proportion of the gp38positive and gp38-negative HPCs among the total HPCs. $(B-E)$ Immunocytochemistry of the gp38-positive $\operatorname{HPCs}(B, D)$ and the gp38-negative HPCs $(C, E)$ (E18.5). Red fluorescence represents AFP $(B, C)$, green fluorescence represents albumin $(D, E)$, and red fluorescence represents CK19 $(D, E)$. Blue fluorescence represents the nucleus stained by DAPI. Scale bars indicate $100 \mu \mathrm{m} .(F)$ The graph represents the proportion of AFP-, albumin-, and CK19-positive cells in both the gp38-positive and gp38-negative HPC fractions (E18.5).
Hex and c-Met genes were expressed preferentially in the gp38-negative HPCs. It was therefore suggested that some genes related to the Wnt signal pathway were up-regulated in the gp38-positive HPCs of E13.5 fetal mice. There was, however, no significant difference in other genes related to the sonic hedgehog and notch signal pathways (Fig. 5).

The effects of the Wnt signal pathway on the cell proliferation and differentiation of HPCs. MTS assay revealed that the doubling time of the gp38-positive HPCs tended to become shorter in the presence of Wnt3a. Furthermore, the doubling time of the gp38-positive HPCs were significantly shorter than that of the gp38-negative HPCs in the presence of Wnt3a. On the other hand, Wnt3a had no obvious effects on the cell proliferation activity of the gp38-negative HPCs (Table 3). To investigate the effect of Wnt3a on the gene expression of the gp38-positive HPCs, quantitative RT-PCR was performed. The AFP, albumin, and CK19 gene expressions of the gp38-positive HPCs cultured in the presence of Wnt3a were examined in comparison to that in the absence of Wnt3a. No significant difference was observed in the gene expression of AFP $(P=0.089)$, albumin $(P=0.071)$ and CK19 $(P=1.000$; Fig. 6). These findings suggested that the activation of the Wnt signal pathway by Wnt3a could tend to stimulate the proliferation without any effects of the differentiation on the gp38-positive HPCs.

\section{Discussion}

The previous analyses of the developmental biology of liver tissue revealed that hepatoblasts expressing AFP differentiated from anterior foregut endoderm at E8.5 with formation of a liver bud (Shiojiri 1981; Belayew and Tilghman 1982; Gualdi et al. 1996). One day after the AFP expression, albumin and CK19 are expressed in hepatoblasts. As fetal livers develop, the AFP and CK19 expressions decrease in hepatoblasts committed to hepatic differentiation, and albumin expression is up-regulated. On the other hand, the AFP and albumin expressions are down-regulated in the hepatoblasts committed to cholangiocyte differentiation, whereas the CK19 expression increases. Hepatoblasts are supposed to have the ability to differentiate into both hepatocytes and cholangiocytes (Shiojiri 1981; Cascio and Zaret 1991; Smas and Sul 1993; Shiojiri et al. 2001). Therefore, hepatoblasts correspond to hepatic progenitor cells.

The CD49f-positive HPCs could be separated by the expression of the surface antigen gp38. Both the gp38positive and the gp38-negative HPCs derived from E13.5 fetal liver expressed the fetal hepatic marker, AFP. 
Figure 5. Microarray analyses comparing the gene expression between the gp38-positive and gp38-negative HPCs. The black bars indicate the gene expression of the gp38-positive HPCs and the white bars show those of the gp38-negative HPCs. Dhh desert hedgehog, Shh sonic hedgehog, Ptch patched homolog, Disp dispatched homolog, Hhat hedgehog acyltransferase, $A F P$ alpha-fetoprotein, $C K 19$ cytokeratin 19.
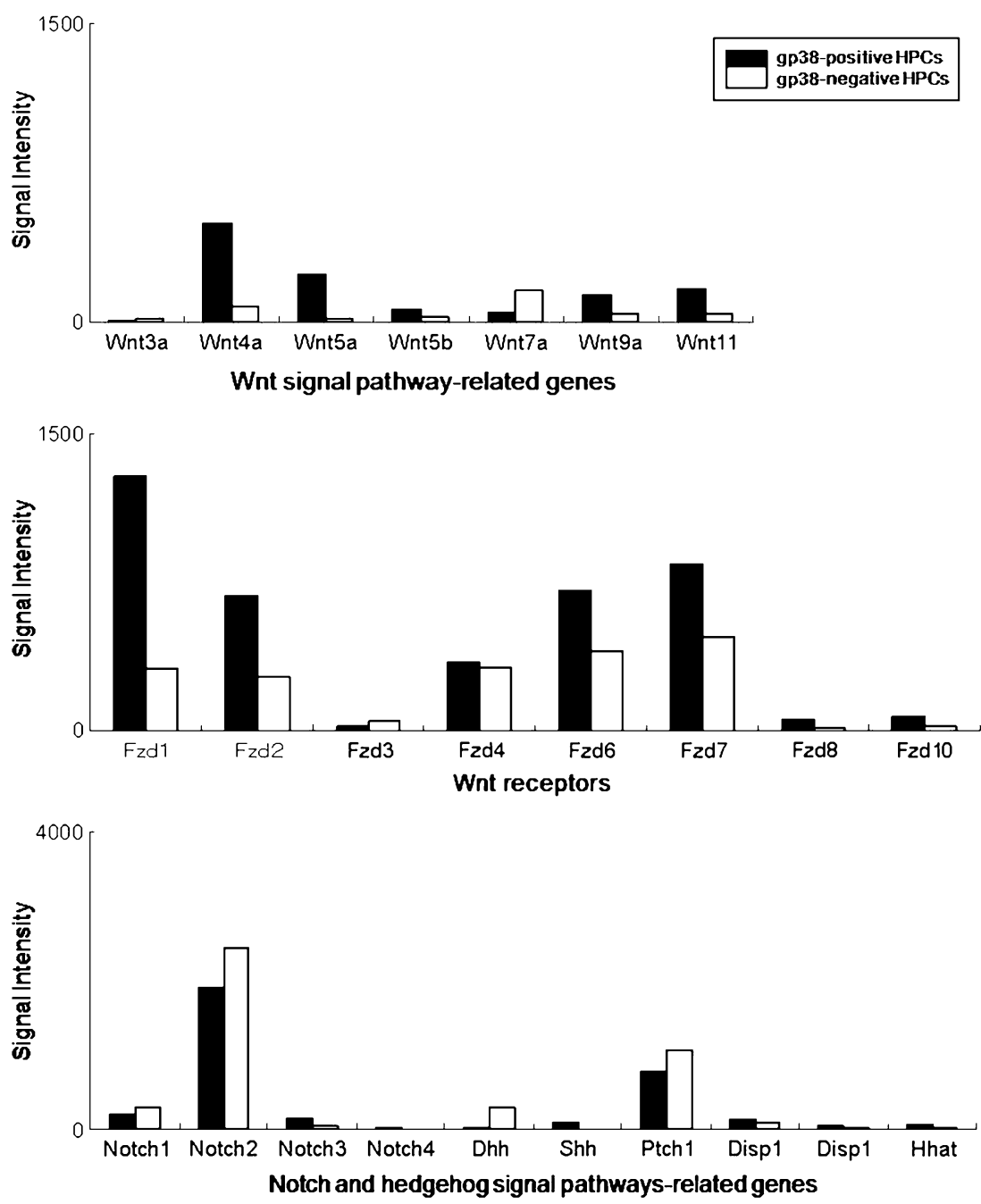

However, the gp38-positive HPCs did not express either of the hepatocyte marker, albumin or the cholangiocytemarker, CK19, while the gp38-negative HPCs did. Furthermore, the gp38-positive HPCs had higher rates of the BrdU

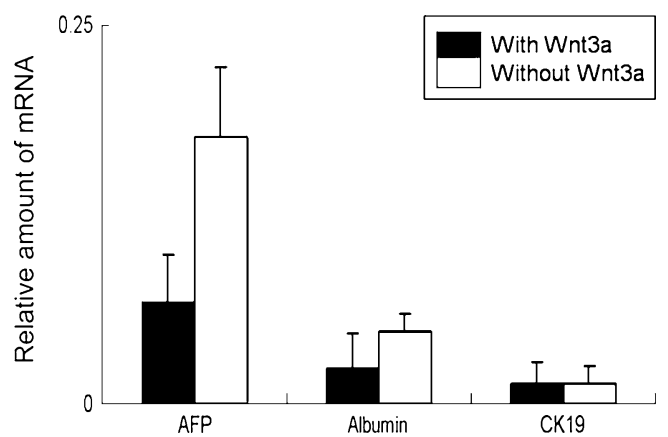

Figure 6. Quantitative PCR analyses were performed to examine the mRNA expression of AFP and albumin and CK19 in the gp38positive HPCs cultured in the presence or absence of Wnt3a. The relative mRNA expressions of AFP and albumin and CK19 were normalized based on that of GAPDH. These results are expressed as the means $\pm \mathrm{SD}$ from triplicate assays. incorporation than the gp38-negative HPCs did, thus indicating the gp38-positive HPCs to have increased proliferative activity in comparison to the gp38-negative HPCs. Therefore, the gp38-positve HPCs appeared to be more immature than the gp38-negative HPCs. Single cell culture assays were tried in order to investigate the selfrenewal ability and the multipotency of the gp38-positive HPCs, which were required to define them as hepatic stem cells. However, these assays were technically difficult because of a significant deterioration in the cell viability after single cell sorting. This was considered to be caused by the inevitable mechanical stress of cell sorting or to indicate their own characteristics after the loss of cell-to-cell contact, which was similar to the characteristics of human embryonic stem cells (Suemori et al. 2006; Ishii et al. 2008).

The proportion of the gp38-positive HPCs decreased gradually until E13.5, thus suggesting the gp38-positive cells to differentiate into the gp38-negative HPCs as fetal livers developed. At E18.5, however, the proportion of the gp38-positive HPCs increased abruptly. The large number 
of the gp38-positive HPCs $(79.2 \pm 7.6 \%)$ at E18.5 expressed CK19, which indicated the differentiation to cholangiocytes, unlike those at E13.5. These findings suggested the characteristics of the gp38-positiveHPCs derived from E18.5 fetal liver were different from those of E13.5. Gp38 is expressed in various cells and tissues of normal human adults, including the kidney podocytes, skeletal muscle, placenta, lung, and heart. In addition, gp38 is up-regulated in squamous cell carcinoma, mesothelioma, and tumors of central nerve system (Wicki and Christofori 2007). Furthermore, some studies reported that bile duct epithelial cells expressed gp38 during the late embryonic to neonatal stage (Schacht et al. 2005). Therefore, the gp38 might be a marker for more immature hepatic progenitor cells only at earlier developmental stages, whereas it could be a marker for cholangiocytes at late developmental stage. In other words, gp 38 might be a stage-specific marker of immature HPCs.

The $\mathrm{Wnt} / \beta$-catenin signaling pathway contributes the maintenance of other stem cells such as hematopoietic stem cells and neural stem cells, and also is involved in hepatocyte proliferation and in hepatic regeneration (Monga et al. 2001, 2003; Reya et al. 2003; Willert et al. 2003; Micsenyi et al. 2004). In the present study, DNA microarray analyses between the gp38-positive and gp38negative HPCs revealed that some genes related to the Wnt signaling pathway were up-regulated in the gp38-positive HPCs. The activation of Wnt signal pathway in the gp38positive HPCs was confirmed by immunocytochemistry of $\beta$-catenin, thus showing the nuclear accumulation of $\beta$ catenin after stimulation by Wnt ligands (data not shown). Although there was no obvious difference in the proliferative activity of the gp38-positive cells in the presence of Wnt5a, $5 \mathrm{~b}, 7 \mathrm{a}$ (data not shown), a progressive tendency was observed in the gp38-positive cells after the administration of Wnt3a. The MTS assay and quantitative RT-PCR revealed that Wnt3a tended to induce cell proliferation of the gp38-positive HPCs, whereas it played no significant role on their differentiation. On the other hand, Wnt5a, 5b, 7a, which were expressed preferentially in the gp38-positive HPCs, had no obvious effect on their proliferation or the gene expression of the gp38positive HPCs (data not shown). Our previous study revealed that the $\mathrm{CD} 49 \mathrm{f}^{+} \mathrm{CD} 45^{-} \mathrm{Thy}^{+}{ }^{+} \mathrm{gp} 38^{-}$mesenchymal cells derived from the fetal murine livers accelerated the cell proliferation of the HPCs by production of some humoral factors (Kamo et al. 2007). This suggests that some soluble stimulators secreted by these mesenchymal cells were necessary to maintain the undifferentiated state of HPCs. Wnt3a, which was shown to have a positive effect on cell proliferation of the gp38-positive HPCs, would be one of the candidates for those factors. However, some other factors would be necessary in combination with Wnt3a.

\section{Conclusions}

The gp38-positive HPCs possessed more immature characteristics of HPCs, thus suggesting they could be candidates for hepatic stem cells. Furthermore, the activation of the Wnt signal pathway tended to maintain the undifferentiated state of the HPCs. These findings are expected to contribute to the elucidation of the molecular mechanisms that underlie hepatic development in the future.

Acknowledgments We thank Dr. Jun K. Yamashita for his valuable assistance with cell sorting and Dr. Andrew G. Farr (University of Washington School of Medicine) for kindly providing the anti-gp38 antibodies. This work was supported by a Grant-in-Aid for Scientific Research from the Japan Society for the Promotion of Science.

Open Access This article is distributed under the terms of the Creative Commons Attribution Noncommercial License which permits any noncommercial use, distribution, and reproduction in any medium, provided the original author(s) and source are credited.

\section{References}

Belayew A.; Tilghman S. Genetic analysis of alpha-fetoprotein synthesis in mice. Mol. Cell. Biol. 2: 1427-1435; 1982.

Breiteneder-Geleff S.; Soleiman A.; Horvat R.; Amann G.; Kowalski H.; Kerjaschki D. Podoplanin-a specific marker for lymphatic endothelium expressed in angiosarcoma. Verh. Dtsch Ges. Pathol. 83: 270-275; 1999.

Cascio S.; Zaret K. Hepatocyte differentiation initiates during endodermal-mesenchymal interactions prior to liver formation. Development 113: 217-225; 1991.

Crosby H.; Kelly D.; Strain A. Human hepatic stem-like cells isolated using c-kit or CD34 can differentiate into biliary epithelium. Gastroenterology 120: 534-544; 2001.

Gualdi R.; Bossard P.; Zheng M.; Hamada Y.; Coleman J.; Zaret K. Hepatic specification of the gut endoderm in vitro: cell signaling and transcriptional control. Genes Dev. 10: 1670 $1682 ; 1996$.

Hoppo T.; Fujii H.; Hirose T.; Yasuchika K.; Azuma H.; Baba S.; Naito M.; Machimoto T.; Ikai I. Thy1-positive mesenchymal cells promote the maturation of CD49f-positive hepatic progenitor cells in the mouse fetal liver. Hepatology 39: 1362-1370; 2004.

Ishii T.; Fukumitsu K.; Yasuchika K.; Adachi K.; Kawase E.; Suemori H.; Nakatsuji N.; Ikai I.; Uemoto S. Effects of extracellular matrixes and growth factors on the hepatic differentiation of human embryonic stem cells. Am. J. Physiol. Gastrointest. Liver Physiol. 295: G313-321; 2008.

Ishii T.; Yasuchika K.; Fujii H.; Hoppo T.; Baba S.; Naito M.; Machimoto T.; Kamo N.; Suemori H.; Nakatsuji N.; Ikai I. In vitro differentiation and maturation of mouse embryonic stem cells into hepatocytes. Exp. Cell Res. 309: 68-77; 2005.

Ishii T.; Yasuchika K.; Machimoto T.; Kamo N.; Komori J.; Konishi S.; Suemori H.; Nakatsuji N.; Saito M.; Kohno K.; Uemoto S.; Ikai I. Transplantation of embryonic stem cell-derived endodermal cells into mice with induced lethal liver damage. Stem Cells 25: 3252-3260; 2007.

Kamo N.; Yasuchika K.; Fujii H.; Hoppo T.; Machimoto T.; Ishii T.; Fujita N.; Tsuruo T.; Yamashita J. K.; Kubo H.; Ikai I. Two populations of Thy1-positive mesenchymal cells regulate in vitro 
maturation of hepatic progenitor cells. Am. J. Physiol. Gastrointest. Liver Physiol. 292: G526-534; 2007.

Kato Y.; Sasagawa I.; Kaneko M.; Osawa M.; Fujita N.; Tsuruo T. Aggrus: a diagnostic marker that distinguishes seminoma from embryonal carcinoma in testicular germ cell tumors. Oncogene 23: 8552-8556; 2004.

Kubota H.; Reid L. Clonogenic hepatoblasts, common precursors for hepatocytic and biliary lineages, are lacking classical major histocompatibility complex class I antigen. Proc. Natl Acad. Sci. USA 97: 12132-12137; 2000.

Micsenyi A.; Tan X.; Sneddon T.; Luo J.; Michalopoulos G.; Monga $\mathrm{S}$. Beta-catenin is temporally regulated during normal liver development. Gastroenterology 126: 1134-1146; 2004.

Monga S.; Monga H.; Tan X.; Mulé K.; Pediaditakis P.; Michalopoulos G. Beta-catenin antisense studies in embryonic liver cultures: role in proliferation, apoptosis, and lineage specification. Gastroenterology 124: 202-216; 2003.

Monga S.; Pediaditakis P.; Mule K.; Stolz D.; Michalopoulos G. Changes in WNT/beta-catenin pathway during regulated growth in rat liver regeneration. Hepatology 33: 1098-1109; 2001.

Oertel M.; Rosencrantz R.; Chen Y.; Thota P.; Sandhu J.; Dabeva M.; Pacchia A.; Adelson M.; Dougherty J.; Shafritz D. Repopulation of rat liver by fetal hepatoblasts and adult hepatocytes transduced ex vivo with lentiviral vectors. Hepatology 37: 994-1005; 2003.

Petersen B.; Grossbard B.; Hatch H.; Pi L.; Deng J.; Scott E. Mouse A6-positive hepatic oval cells also express several hematopoietic stem cell markers. Hepatology 37: 632-640; 2003.

Reya T.; Duncan A.; Ailles L.; Domen J.; Scherer D.; Willert K.; Hintz L.; Nusse R.; Weissman I. A role for Wnt signalling in self-renewal of haematopoietic stem cells. Nature 423: 409-414; 2003.

Sandhu J.; Petkov P.; Dabeva M.; Shafritz D. Stem cell properties and repopulation of the rat liver by fetal liver epithelial progenitor cells. Am. J. Pathol. 159: 1323-1334; 2001.

Schacht V.; Dadras S.; Johnson L.; Jackson D.; Hong Y.; Detmar M. Up-regulation of the lymphatic marker podoplanin, a mucin-type transmembrane glycoprotein, in human squamous cell carcinomas and germ cell tumors. Am. J. Pathol. 166: 913-921; 2005.

Shiojiri N. Enzymo- and immunocytochemical analyses of the differentiation of liver cells in the prenatal mouse. J. Embryol. Exp. Morphol. 62: 139-152; 1981.

Shiojiri N.; Inujima S.; Ishikawa K.; Terada K.; Mori M. Cell lineage analysis during liver development using the spf(ash)-heterozygous mouse. Lab. Invest. 81: 17-25; 2001.

Smas C.; Sul H. Pref-1, a protein containing EGF-like repeats, inhibits adipocyte differentiation. Cell 73: 725-734; 1993.

Suemori H.; Yasuchika K.; Hasegawa K.; Fujioka T.; Tsuneyoshi N.; Nakatsuji N. Efficient establishment of human embryonic stem cell lines and long-term maintenance with stable karyotype by enzymatic bulk passage. Biochem. Biophys. Res. Commun. 345: 926-932; 2006.

Suzuki A.; Zheng Y.; Kaneko S.; Onodera M.; Fukao K.; Nakauchi $\mathrm{H}$.; Taniguchi $\mathrm{H}$. Clonal identification and characterization of self-renewing pluripotent stem cells in the developing liver. $J$. Cell Biol. 156: 173-184; 2002.

Tanimizu N.; Nishikawa M.; Saito H.; Tsujimura T.; Miyajima A. Isolation of hepatoblasts based on the expression of Dlk/Pref-1. J. Cell Sci. 116: 1775-1786; 2003.

Wicki A.; Christofori G. The potential role of podoplanin in tumour invasion. Br. J. Cancer 96: 1-5; 2007.

Willert K.; Brown J.; Danenberg E.; Duncan A.; Weissman I.; Reya T.; Yates J. R.; Nusse R. Wnt proteins are lipid-modified and can act as stem cell growth factors. Nature 423: 448-452; 2003.

Yasuchika K.; Hirose T.; Fujii H.; Oe S.; Hasegawa K.; Fujikawa T.; Azuma H.; Yamaoka Y. Establishment of a highly efficient gene transfer system for mouse fetal hepatic progenitor cells. Hepatology 36: 1488-1497; 2002.

Yin L.; Sun M.; Ilic Z.; Leffert H.; Sell S. Derivation, characterization, and phenotypic variation of hepatic progenitor cell lines isolated from adult rats. Hepatology 35: 315-324; 2002. 